Article

\title{
Insulin-Sensitizer Effects of Fenugreek Seeds in Parallel with Changes in Plasma MCH Levels in Healthy Volunteers
}

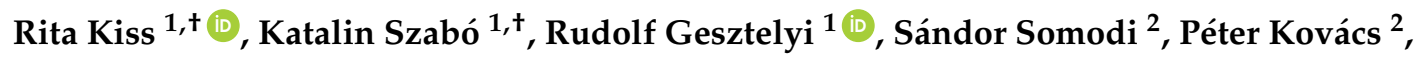 \\ Zoltán Szabó ${ }^{3}$, József Németh ${ }^{1}$, Dániel Priksz ${ }^{1}$, Andrea Kurucz ${ }^{1}$, Béla Juhász ${ }^{1, *}$ and \\ Zoltán Szilvássy ${ }^{1}$ \\ 1 Department of Pharmacology and Pharmacotherapy, Faculty of Medicine, University of Debrecen, \\ H-4032 Debrecen, Hungary; kiss.rita@med.unideb.hu (R.K.); szabo.katalin@pharm.unideb.hu (K.S.); \\ gesztelyi.rudolf@pharm.unideb.hu (R.G.); nemeth.jozsef@med.unideb.hu (J.N.); \\ priksz.daniel@pharm.unideb.hu (D.P.); kurucz.andrea@pharm.unideb.hu (A.K.); \\ szilvaszilva99@gmail.com (Z.S.) \\ 2 Department of Internal Medicine, Faculty of Medicine, University of Debrecen, H-4032 Debrecen, Hungary; \\ somodi@belklinika.com (S.S.); kovacsp@belklinika.com (P.K.) \\ 3 Department of Emergency Medicine, Faculty of Medicine, University of Debrecen, H-4032 Debrecen, \\ Hungary; szaboz.med@gmail.com \\ * Correspondence: juhasz.bela@med.unideb.hu; Tel.: +36-5242-7899 (ext. 56109) \\ + These authors contributed equally to this work.
}

Received: 28 December 2017; Accepted: 2 March 2018; Published: 8 March 2018

\begin{abstract}
In developed, developing and low-income countries alike, type 2 diabetes mellitus (T2DM) is one of the most common chronic diseases, the severity of which is substantially a consequence of multiple organ complications that occur due to long-term progression of the disease before diagnosis and treatment. Despite enormous investment into the characterization of the disease, its long-term management remains problematic, with those afflicted enduring significant degradation in quality-of-life. Current research efforts into the etiology and pathogenesis of T2DM, are focused on defining aberrations in cellular physiology that result in development of insulin resistance and strategies for increasing insulin sensitivity, along with downstream effects on T2DM pathogenesis. Ongoing use of plant-derived naturally occurring materials to delay the onset of the disease or alleviate symptoms is viewed by clinicians as particularly desirable due to well-established efficacy and minimal toxicity of such preparations, along with generally lower per-patient costs, in comparison to many modern pharmaceuticals. A particularly attractive candidate in this respect, is fenugreek, a plant that has been used as a flavouring in human diet through recorded history. The present study assessed the insulin-sensitizing effect of fenugreek seeds in a cohort of human volunteers, and tested a hypothesis that melanin-concentrating hormone $(\mathrm{MCH})$ acts as a critical determinant of this effect. A test of the hypothesis was undertaken using a hyperinsulinemic euglycemic glucose clamp approach to assess insulin sensitivity in response to oral administration of a fenugreek seed preparation to healthy subjects. Outcomes of these evaluations demonstrated significant improvement in glucose tolerance, especially in patients with impaired glucose responses. Outcome data further suggested that fenugreek seed intake-mediated improvement in insulin sensitivity correlated with reduction in $\mathrm{MCH}$ levels.
\end{abstract}

Keywords: hyperinsulinemic euglycemic glucose clamp (HEGC); fenugreek; melanin-concentrating hormone (MCH); RIA; type 2 diabetes; clinical pilot study 


\section{Introduction}

\subsection{Major Pathologic Features of T2DM}

Type 2 diabetes mellitus, T2DM or NIDDM (non-insulin-dependent diabetes mellitus) is a metabolic disorder characterized by hyperglycemia, insulin resistance and relative insulin deficiency. Its primary pathomechanism is persistent hyperglycemia, due to inability of a subject's cells to induce adequate metabolic responses to insulin produced by pancreatic $\beta$ islet cells. A major feature of the disease is the inability of an individual's insulin to maintain normoglycemia. Major consequences occurring due to reduced insulin sensitivity by tissues for which glycemic balance is particularly important, such as adipose tissue muscles, liver, may be very severe [1-6].

\subsection{Mechanisms Contributing to T2DM Onset And Progression}

T2DM is often associated with obesity and pathologically altered lipid metabolism [7]. The pathogenesis of the disorder also involves aberrant alteration in levels and function of many centrally or peripherally acting hormones and peptides, including: insulin, leptin, ghrelin, glucagon-like peptide-1 (GLP-1), melanin-concentrating hormone (MCH) and many others. T2DM is the most common form of diabetes with a proportion of 90-95\% compared to T1DM [8]. Its incidence is gradually growing, and professionals and organizations, including the World Health Organization (WHO) and the American Diabetes Association predict that by 2030 we will face a kind of "diabetes epidemic" [2,4,9-11].

\subsection{Countermeasures to T2DM Progression}

This diabetic condition usually can be controlled by lifestyle changes, including general diet, use of dietary supplements and/or oral antidiabetic agents [12-15]. The objective of these strategies, which is to normalize blood glucose, is increasingly aided by identification of agents based on generally regarded as safe (GRAS) plant materials, some of which, such as fenugreek (Trigonella foenum graecum/TFG), are generally widely represented in the human diet. Fenugreek is one of the oldest medicinal plants, endemic to India and North Africa [16,17]. Currently it is widely cultivated worldwide, especially in the Mediterranean region. Both seeds and leaves of fenugreek are widely used as a culinary spice (to enhance the taste of many meat or vegetable dishes) $[18,19]$. The seeds are used as a therapeutic supplement for numerous indications: as an appetite stimulant, to treat digestive disorders, to increase milk production in lactating women and treatment of hyperlipidemia and diabetes [20,21]. The major bioactive components of fenugreek seeds include: alkaloids, amino acids, flavonoids, fibers, coumarin, lipids, vitamins, minerals, notable saponins and steroidal sapogenins, of which those of most intensive interest, are yamogenin and diosgenin $[16,22,23]$. Fenugreek seeds possess well known therapeutic effects, the most important of which include their antidiabetic activity, related regulation of food intake and mood disorders. They additionally exhibit antioxidant, hypolipidemic, cardioprotective and gastroprotective effects, immunoregulatory, antimicrobial, anti-inflammatory activities and analgesic properties. Moreover, recent studies of the seeds demonstrate that their components are agonists on the MCHR1 isoform of MCHRs (melanin-concentrating hormone receptor) [18,24-27].

\subsection{MCH Properties}

$\mathrm{MCH}$ is a cyclic peptide that was first isolated and purified from salmon pituitary gland and structurally characterized by Kawauchi et al., in 1983 [28]. Originally, its primary biological function was considered to be skin paling in fish [29,30]. Further investigation revealed mammalian $\mathrm{MCH}$ expression, with potential for a diverse range of functions. In mammals, $\mathrm{MCH}$ is a nonadecapeptide produced in the hypothalamus and secreted predominantly in neurons of the lateral hypothalamic area (LHA) and zona incerta (ZI) in the subthalamus. Moreover, its presence has been demonstrated in peripheral tissues, including pancreatic $\beta$-cells, colonic epithelial cells and adipocytes [31-36]. 


\subsection{MCHR Distribution and Major Activities}

The effects of $\mathrm{MCH}$ are mediated by two receptors belonging to the G-protein-coupled receptor family: MCH-R1 and MCH-R2 [30]. Expression of MCH-R1 is the highest in the ventromedial and dorsomedial nuclei of the hypothalamus, and both appear to be regulators of food intake [37]. Additional roles for these hormones have been shown in diabetes, obesity, and gastrointestinal and mood disorders. In most sources, this isoform exhibits approximately $38 \%$ homogeneity with MCH-R1 $[29,30,38]$. The biological function of MCH-R2 remains undefined at the time of this writing, but its wide expression in the brain and expression patterns in peripheral tissues, suggest diverse regulatory functions $[39,40]$. Investigation of this molecule has additionally revealed that MCH-R2 expression is different than that of the $\mathrm{MCH}-\mathrm{R} 1$ isoform in certain areas of the brain, including olfactory tissue, nucleus accumbens, amygdala along with hippocampal, hypothalamic cells. MCH-R1 expression is typically limited to the cortical area of the brain and it is not present in the periphery [41].

\subsection{Differential Effects of $\mathrm{MCH}$ and Relevance to Diabetes Research}

Accordingly, stimulation of each of these two isoforms is expected to have differential effects on neurologic function and downstream effects (that may possibly be in the opposite direction) [41,42]. $\mathrm{MCH}$ thus appears to be an important mediator of metabolic processes, food intake, energy expenditure, obesity, mood control, stress and sleep-wake cycles. Intriguingly, in the context of the investigation described by this report, recent studies have demonstrated a role for $\mathrm{MCH}$ in the regulation of pancreatic beta-cell function [43-47], findings which led the authors of this report to speculate that bioactive components of fenugreek seeds may exert medically useful effects on these processes.

\subsection{Objectives of Present Investigation}

The study described in the present report was undertaken to evaluate a hypothesis that an orally administered preparation of fenugreek seeds reduces hyperglycemia through insulin sensitization. The investigation further assessed the safety and tolerance of repetitive short interval administration of fenugreek seed preparation for a given subject during a ten-day period. A corollary hypothesis tested in the present study is that melanin-concentrating hormone $(\mathrm{MCH})$ is a critical component of T2DM-associated changes in insulin sensitization.

\section{Results}

\subsection{Fasting Serum Glucose Levels in Placebo- and Fenugreek-Treated Subjects}

To adjust the rate of glucose infusion, it was necessary to determine the fasting blood glucose levels. As expected, there were no statistically significant differences in the fasting serum glucose levels among the fenugreek- or placebo-treated groups (Figure 1). 


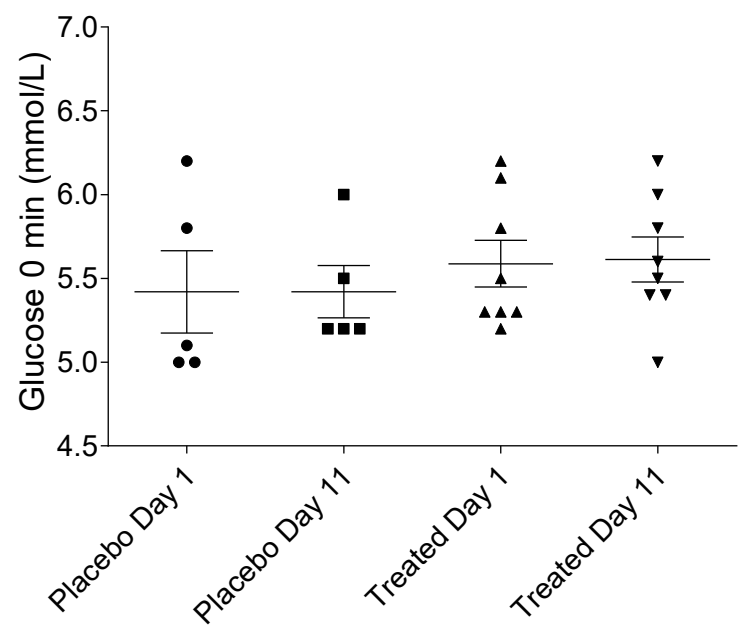

Figure 1. Fasting serum glucose levels in the placebo- and fenugreek-treated subjects. No significant differences were found among groups.

\subsection{Fasting Plasma Insulin Levels of the Placebo- and Fenugreek-Treated Subjects}

Determining the fasting insulin level is necessary to calculate derived parameters and also for the safe execution of HEGC procedure. The baseline insulin levels were in the normal ranges for all of the volunteers, and no significant differences were found between the fasting plasma insulin levels of the fenugreek- and placebo-treated groups (Figure 2).

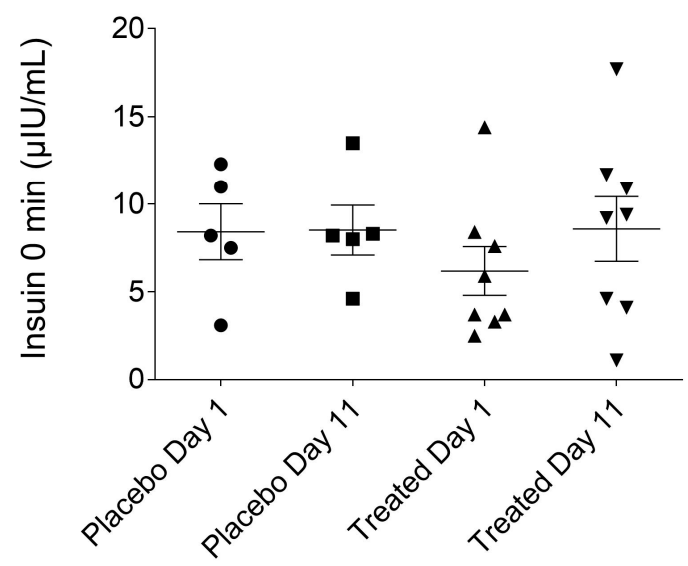

Figure 2. Fasting plasma insulin levels of the placebo- and fenugreek-treated subjects.

\subsection{Effects of TFG on Glucose Infusion Rate (GIR)}

During the hyperinsulinemic euglycemic glucose clamp (HEGC) examination, the steady-state glucose infusion rate significantly increased among the fenugreek-treated volunteers, referring to the insulin-sensitizing effect of the TFG (Table 1 and Figure 3). It is notable that GIR values of the TFG-treated group were significantly lower at the baseline point (before the initiation of the treatment). Although, patients were randomly divided into groups, two subjects with diminished GIR were sorted to the TFG group, as it turned out during the HEGC procedure. Interestingly, TFG-treatment exerted the most powerful effect in these two cases (increasing GIR up to $100 \%$ ). 
Table 1. (A) Influence of TFG (Trigonella foenum graecum) on GIR (Glucose Infusion Rate) in the placeboand fenugreek-treated subjects. ${ }^{* *}$ represents statistically significant difference $(p<0.01)$ compared to the Day 1 TFG group; (B) Individual GIR values of volunteers in Placebo and TFG-treated group. GIR is expressed as $\mathrm{mg} / \mathrm{kg} / \mathrm{min}$.

\begin{tabular}{|c|c|c|c|c|}
\hline \multicolumn{5}{|c|}{ (A) } \\
\hline Summary & GIR (mg/kg/min) & GIR (mg/kg/min) & GIR $(\mathrm{mg} / \mathrm{kg} / \mathrm{min})$ & GIR $(\mathrm{mg} / \mathrm{kg} / \mathrm{min})$ \\
\hline & $\begin{array}{c}\text { Day } 1 \\
(\text { Placebo, } n=5)\end{array}$ & $\begin{array}{c}\text { Day } 11 \\
(\text { Placebo, } n=5)\end{array}$ & $\begin{array}{c}\text { Day } 1 \\
(\mathrm{TFG}, n=8)\end{array}$ & $\begin{array}{c}\text { Day } 11 \\
(\mathrm{TFG}, n=8)\end{array}$ \\
\hline Mean & 8.45 & 8.5 & 6.63 & $8.13 * *$ \\
\hline S.D. & 3.07 & 2.86 & 3.65 & 3.01 \\
\hline \multicolumn{5}{|c|}{ (B) } \\
\hline Individual GIR & $\begin{array}{c}\text { Day } 1 \\
(\text { Placebo, } n=5)\end{array}$ & $\begin{array}{c}\text { Day } 11 \\
(\text { Placebo, } n=5)\end{array}$ & $\begin{array}{c}\text { Day } 1 \\
(\mathrm{TFG}, n=8)\end{array}$ & $\begin{array}{c}\text { Day } 11 \\
(\mathrm{TFG}, n=8)\end{array}$ \\
\hline 1. & 4.99 & 5.79 & 6.49 & 7.46 \\
\hline 2. & 6.99 & 6.69 & 2.04 & 4.86 \\
\hline 3. & 12.34 & 12.23 & 6.05 & 8.09 \\
\hline 4. & 7.0 & 6.9 & 4.39 & 6.96 \\
\hline 5. & 10.95 & 10.87 & 2.52 & 4.14 \\
\hline 6. & & & 10.09 & 10.84 \\
\hline 7. & & & 12.14 & 13.02 \\
\hline 8. & & & 9.34 & 9.45 \\
\hline Mean & 8.454 & 8.496 & 6.633 & 8.125 \\
\hline S.D. & 3.065 & 2.86 & 3.645 & 3.005 \\
\hline
\end{tabular}

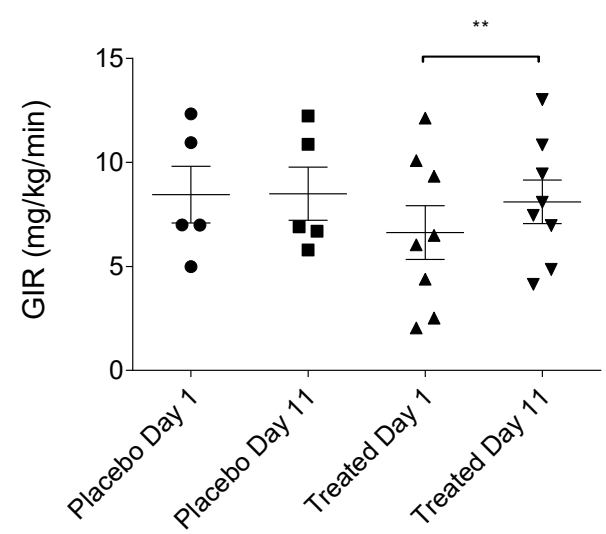

Figure 3. GIR in the placebo- and fenugreek-treated subjects. ${ }^{* *}$ refers to statistically significant difference $(p<0.01)$ between Day 1 and Day 11 in the treated group.

\subsection{Serum Lipid Levels of the Placebo- and Fenugreek-Treated Subjects}

Figure 4 represents our results showing no statistically significant differences in the serum lipid parameters (total cholesterol, triglycerides, low-density lipoprotein (LDL) and high-density lipoprotein (HDL)-cholesterol) of the fenugreek- and placebo- treated groups. 

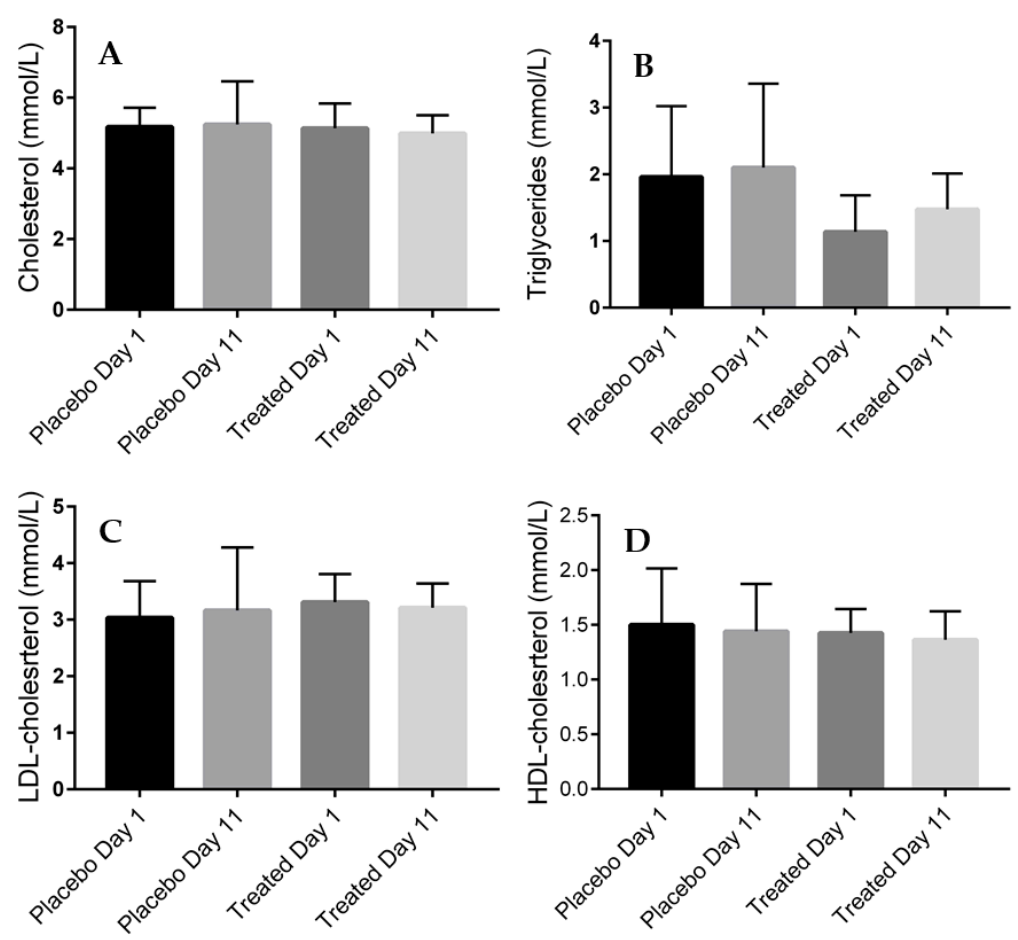

Figure 4. Serum lipid levels of the placebo- and fenugreek-treated subjects. (A) serum total-cholesterol levels (mmol/L); (B) serum triglyceride levels (mmol/L); (C) high-density lipoprotein (HDL)-cholesterol levels (mmol/L); (D) low-density lipoprotein (LDL)-cholesterol levels (mmol/L).

\subsection{Calculated Parameters of Insulin Sensitivity Assessment (MCRI, ISI, QUICKI, HOMA-IR and} HOMA-\% $\beta)$ in the Placebo- and Fenugreek-Treated Subjects

MCRI (metabolic clearance rate of insulin), ISI (insulin sensitivity index), QUICKI (quantitative insulin sensitivity check index), HOMA-IR (homeostatic model assessment-insulin resistance) or HOMA-B (homeostatic model assessment-beta-cell function) indices were calculated to precisely assess insulin sensitivity. Our results presented in Figures $5-8$, show that no statistically significant difference could be observed in the values of the abovementioned indices between the fenugreekand placebo-treated groups. Steady-state insulin levels used for calculations are presented in Supplementary Material section (Supplementary Table S5) of this paper.

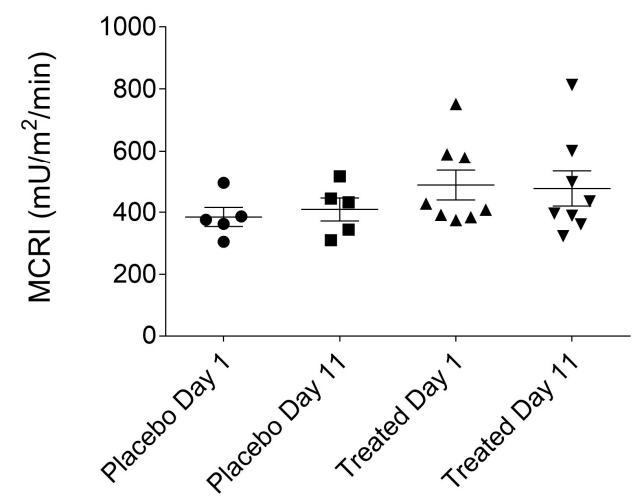

Figure 5. MCRI (metabolic clearance rate of insulin) of the placebo- and fenugreek-treated subjects. 


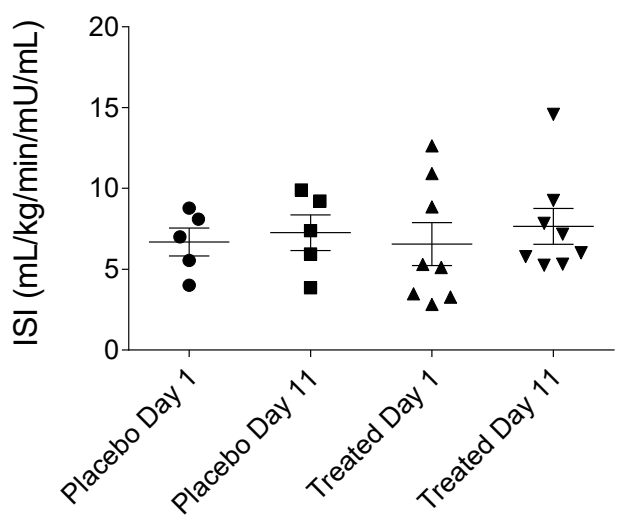

Figure 6. Insulin sensitivity index of the placebo- and fenugreek-treated subjects.

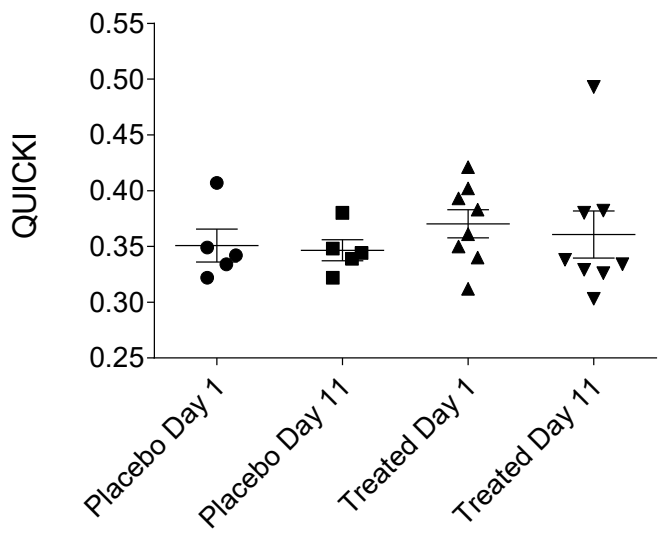

Figure 7. QUICKI (quantitative insulin sensitivity check index) of the placebo- and fenugreek-treated subjects.
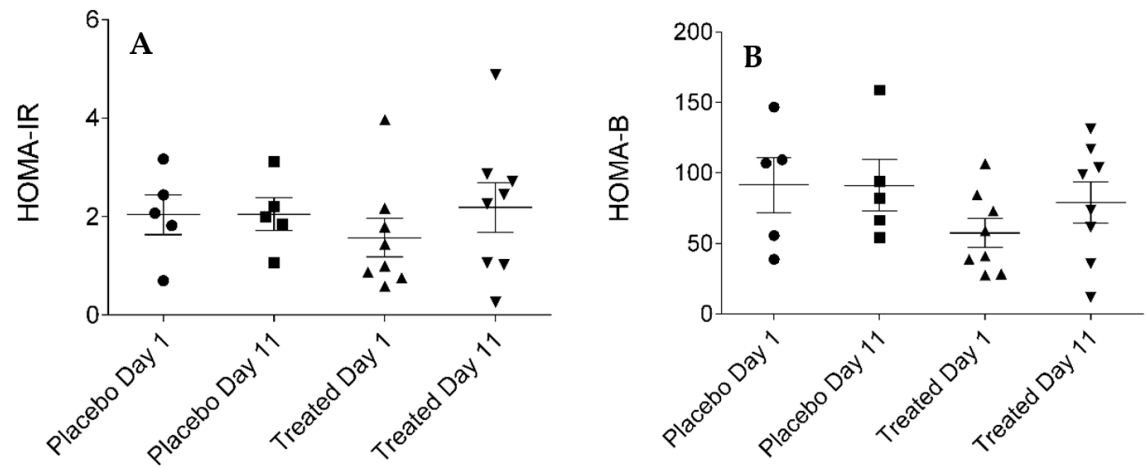

Figure 8. HOMA-IR (homeostatic model assessment-insulin resistance, (A) and HOMA-B (homeostatic model assessment-beta cell function, (B) of the placebo- and fenugreek-treated subjects.

\subsection{Effect of TFG on Plasma MCH Levels}

Plasma $\mathrm{MCH}$ concentrations were measured by a highly specific and sensitive radioimmunoassay (RIA) method developed recently by our team, as is described in Section 4.8. Our assumption is partially confirmed by the fact that after ten days of Fenugreek treatment, plasma $\mathrm{MCH}$ concentration was significantly reduced in the TFG-treated group, when measured prior to HEGC ( 0 min sample). On the contrary, no statistically significant differences were found in the $\mathrm{MCH}$ plasma concentrations after 120 min of the HEGC procedure, as shown in Figure 9. 


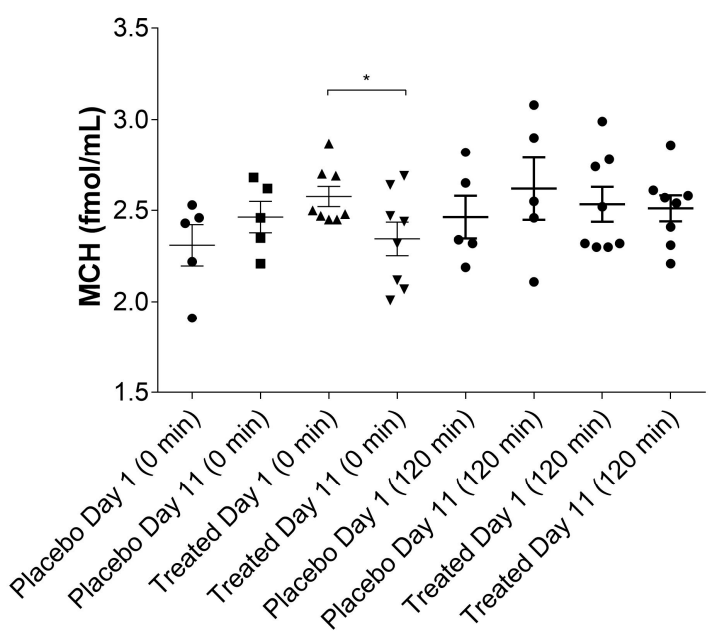

Figure 9. $\mathrm{MCH}$ (melanin-concentrating hormone) levels of the placebo- and fenugreek-treated subjects.

* represents significant difference $(p<0.05)$ between Day 1 and Day 11 in the treated group.

\subsection{Correlation between $\mathrm{MCH}$ and Serum Lipid Levels}

Analyzing the relationship between plasma $\mathrm{MCH}$ concentration and serum lipid levels of fenugreek-treated volunteers, we observed that elevation of plasma $\mathrm{MCH}$ level may be associated with a decreasing concentration of total cholesterol, including LDL- and HDL-cholesterol, and although the differences do not reach the level of statistical significance, a clear tendency can be seen (Supplementary Tables S1 and S2). In parallel, we showed a negative correlation between the $\mathrm{MCH}$ and triglyceride levels. Data is presented in Supplementary Material, in Supplementary Tables S1 and S2.

\subsection{Correlation between MCH and Serum Glucose Levels}

Analyzing the correlation between the peripheral expression of $\mathrm{MCH}$ and serum glucose concentrations we did not observe any statistically significant association between the MCH and glucose levels in placebo- and fenugreek-treated volunteers (data in Supplementary Table S3).

\subsection{Correlation between $\mathrm{MCH}$ and Plasma Insulin Levels}

Our results indicate that no statistically significant correlation could be detected between the $\mathrm{MCH}$ and insulin plasma concentration (data presented in Supplementary Table S4).

\section{Discussion}

Outcomes of the experiments conducted in the present investigation demonstrate that fenugreek seed does indeed exhibit insulin-sensitizing effects in tissues. Evidence for this conclusion is based on observations that glucose infusion rate (GIR) values significantly increased in participating subjects, following ten-day treatment periods with fenugreek seed preparations $(p=0.001327)$. The largest increases in GIR, corresponding to an insulin sensitizing effect of $97 \%$, occurred in two patients with the lowest GIR values in the test group, measured before initiation of treatment. GIR increases were also observed in the other six volunteers treated with fenugreek capsules, however, to a much lesser extent than in the two subjects with the lowest measured GIRs. In contrast, placebo-treated subjects, failed to exhibit significant change in GIR values. According to the abovementioned findings, we may conclude that the TFG-treatment is more effective when the patient is insulin-resistant, and that it does not have influence on glucose homeostasis under normal, physiological conditions. Additionally, no significant placebo-associated changes were observed in MCRI, QUICKI, ISI, HOMA-IR, and HOMA-B, serum glucose, plasma insulin and serum lipids. Interpretation of these data is, nevertheless, subject to the caveat that the present study is a preliminary analysis of fenugreek seed effects and not intended 
as a definitive analysis of T2DM pathomechanism. Here, the sample ' $n$ ' for test subjects is low, and it is anticipated that more comprehensive future studies will involve participation of larger groups of volunteers. Nevertheless, results of this small pilot study are encouraging, since safety and efficacy of fenugreek seeds have been proven in human subjects, with parallel changes in the plasma level of $\mathrm{MCH}$, a mediator that may play an important role in glucose-homeostasis. Future clinical and basic lab analyses of this biomaterial, planned by the authors, will extend the experiments described here into detailed characterization of signaling processes contributing to insulin sensitization that are sensitive to modulation by fenugreek and other natural products. Such investigations will be conducted in tandem with evaluations of currently available insulin-sensitizing drugs to determine the capability of natural substances, to potentiate their pharmacological value and reduce occurrence of side effects. Haines et al. have previously conducted product development research that achieved these objectives [48]. A major outcome of the present study included an observation that following ten days of fenugreek seed ingestion, serum MCH levels were significantly reduced $(p=0.0464)$, while no such reduction was observed in the placebo-treated group. These results demonstrate that fenugreek-mediated augmentation of insulin sensitization and improved glucose metabolism correlate with and may be substantially dependent on decrease of $\mathrm{MCH}$ levels. The $\mathrm{MCH}$ is involved in several physiological functions in vertebrates. Evidence suggests its crucial role in energy homeostasis, food intake, obesity and T2DM. The increased levels of MCH is correlated with hyperphagia, body weight gain, increased white adipose tissue and liver mass, reduce brown adipose tissue function, moreover, elevated $\mathrm{MCH}$ may produce hyperglycemia, hyperinsulinemia, and hyperleptinemia [49-54]. On the contrary, $\mathrm{MCH}-\mathrm{knockout}$ mice are lean and resistant to obesity, furthermore, resistant to age-related glucose intolerance [55]. In the periphery, $\mathrm{MCH}$ was detected in several tissues, e.g., in the beta cells of the pancreatic islets, adipose tissues and in the duodenum. $\mathrm{MCH}$ induces islet hyperplasia, which suggest that it may regulate pancreatic islet secretory function and beta cell dynamics [35,36,56,57]. Moreover, Pereira-da-Silva et al. suggested that MCH may act as the central modulator of insulin activity, as it could modify glucose metabolism [45]. MCH-containing neurons and $\mathrm{MCH}$ receptors have a critical role in energy homeostasis. These (second order and downstream) neurons regulated by POMC (proopio-melanocortin) and NPY / AGRP (neuropeptide Y / agouti-related peptide) (first-order) neurons and modulate food intake. First order neurons can process the signals arriving from the periphery like ghrelin, insulin and leptin. NPY / AGRP will stimulate and POMC will inhibit MCH-containing neurons. Ghrelin act as a positive modulator on NPY/AGRP; thus, if the MCH levels will increase, food intake will be enhanced. Effects of insulin and leptin are antagonistic, whereby POMC neurons will be stimulated by these hormones, thus, $\mathrm{MCH}$-containing neurons will be inhibited and food intake will decrease. MCH-containing neurons are negatively affected by autoregulation as well [58]. Furthermore, $\mathrm{MCH}$-containing neurons not only secrete $\mathrm{MCH}$, but also produce GABA (gamma-amino butyric acid), CART (cocaine- and amphetamine-regulated transcript) and nesfatin. These neurons can be directly activated by orexinergic neurons, and indirectly by glutamate release from excitatory fibers. In contrast, $\mathrm{MCH}$ inhibits orexinergic neurons and the neighboring GABAergic fibers. Furthermore, $\mathrm{MCH}$-containing neurons may be inhibited by $\mathrm{MCH}$, GABA, NE (norepinephrine, mediated by alpha-2 receptors), serotonin, acetylcholine (muscarinic), neuropeptide $Y$ and histamine [59]. Interestingly, Hausen et al. found that insulin can act directly on $\mathrm{MCH}$-containing neurons, which resulted in impairment of locomotor activity and insulin sensitivity [60]. This is a reasonable interpretation of the data, since elevated levels of the hormone are associated with increase in the food intake and, thus, body weight, and with an increased rate of preadipocyte differentiation [61].

To investigate the correlation between the MCH and glucose, as well as lipid metabolism, we measured the blood levels of the correspondent parameters. Although literature data presents an important decrease in the aforementioned blood parameters after fenugreek treatment, it is important to highlight the major differences between these study designs and our experimental concept. Accordingly, numerous experimental and clinical reports are available, but all enrolled patients with impaired glucose tolerance, prediabetes or manifest T2DM, while in our study, only 
healthy volunteers were examined $[8,62,63]$. Another important difference was that our volunteers were treated with a lower daily dose of TFG, $3 \mathrm{~g} /$ day instead of $10 \mathrm{~g} /$ day used by others $[8,62,63]$. Finally, we treated the volunteers only for ten days, in particular interest to short-term effects of TFG-treatment $[8,62,63]$. Probably due to these differences, we failed to find significant changes in fasting glucose, insulin or serum lipid concentrations. However, to our knowledge, this is the first study to demonstrate that fenugreek seeds may contribute to the regulation of glucose metabolism by restoring the insulin sensitivity of peripheral tissues, shown by the most sensitive method (HEGC) on human volunteers. Moreover, we observed that the fasting insulin level is higher in the TFG-treated group at the end of the study, probably due to the insulinotropic effect of the fenugreek seeds [64-66].

Another novel finding is that MCH-like immonoreactivity, measured by a highly specific method developed by our team, increased significantly in the treated group after ten days of treatment, when measured from blood samples at the 0 time point, before HEGC was carried out. This difference was blurred away when measuring MCH levels after the HEGC procedure, nevertheless, a possible explanation could be that serum levels of $\mathrm{MCH}$ - which is an orexigenic hormone responsible for energy homeostasis-alter when glucose is administered during the HEGC procedure. We consider baseline levels more reliable, and the decrease observed in the treated group is more convincing, especially if we count the fact that fasting increases $\mathrm{MCH}$ serum levels, as was shown by Gavrila et al. [31]. According to the preliminary results shown here, we conclude that it would be valuable to investigate effects of TFG on MCH levels in a larger number of patients who manifest T2DM. MCH-related signal transduction pathways could become new molecular targets of drug discovery and development in the future.

\section{Experimental Section}

\subsection{Study Design}

The study was a double-blind, multiple-dose, randomized, placebo controlled, single treatment period pilot study, entitled: "A pilot clinical study in healthy volunteers of the ten days multiple dose (three times daily $1000 \mathrm{mg}$ ) administration of Fenugreek capsules (the Hungarian product: Dr. Makai Görögszénamag) to evaluate the suspected insulin sensitizing effect behind the glycemic control of the treatment well-established in animal and human trials (Pilot study)". The study was conducted at the Clinical Pharmacology Department at the University of Debrecen in the period 31 January-20 February 2017 and was sponsored by Libafood-Tech KFT Hungary (Debrecen, Hungary).

\subsection{Ethical Considerations}

The Clinical Study Protocol was authorized by the National Office of the Chief Medical Officer (Hungary) (IF-911-2/2017, dated: 11 January 2017) based on the Ethical Approval of the Medical Research Council-Scientific Research Ethics Committee (Hungary) of 9 January 2017 (ETT TUKEB: 1930-1/2017/EKU). The protocol was performed in compliance with International Council on Harmonization ( $\mathrm{ICH}$ ) Guidelines for Good Clinical Practices, and with the principles of the Helsinki Declaration.

\subsection{Subject Recruitment}

The volunteers enrolled in the study were recruited from students, employees of the University and outsiders based on a preliminary screening test. The patients were informed before the study orally and in a written form at a volunteer meeting and every volunteers signed the ICFs. Within 21 days prior to the start of the clinical study, the volunteers were taken under physical and ECG examination, respectively. Routine clinical laboratory tests, including Human Immunodeficiency Virus (HIV), Hepatitis B Virus Surface Antigen (HBsAG), drugs of abuse and pregnancy tests were also performed. Thirteen volunteers were enrolled in this pilot study: 6 males and 7 females, of which 2 males in Placebo and 4 males in TFG-treated group, accordingly 3 females in Placebo and 4 females 
in TFG-treated group. The age of the volunteers ranged from 23 to 55 years (Mean $=30.07, \mathrm{SD}=10.06$ ). In the Placebo group the age of probands ranged from 23 to 37 years (Mean $=28.00 ; S D=5.57$ ) and in the TFG treated group from 31 to 55 years (Mean $=42.75 ; \mathrm{SD}=8.86$ ). The BMI of the volunteers ranged between 19.89 and 31.62 (Mean $=25.80$ ). In the Placebo group the BMI of probands ranged from 19.89 to 28.76 (Mean $=23.75 ; \mathrm{SD}=3.38$ ) and in the TFG treated group from 22.68 to 31.62 (Mean $=27.08$; $\mathrm{SD}=2.07)$. The acceptance of volunteers was based on the inclusion and exclusion criteria, and were randomly separated into placebo (5) and treatment (8) groups using a computer-generated randomization code.

\subsection{Inclusion and Exclusion Criteria}

Healthy, non-smoker and non-pregnant, 18-60 years old volunteers, with BMI (body mass index) $=18.5-30 \mathrm{~kg} / \mathrm{m}^{2}$, normal ECG and vital signs were included. Patients with asthma, allergic reactions, cardiovascular, respiratory, kidney, liver, endocrine and neurological diseases or psychiatric disorders in the medical history were excluded from the study. Other exclusion criteria included smoking, alcoholism, pregnancy, lactation, viral infections, medical therapy in the last 2 weeks, participation in another clinical study in the last 30 days.

\subsection{Used Products}

Test product: Dr. MAKAI Fenugreek, with active ingredient: Trigonella foenum-graecum, in $500 \mathrm{mg}$ hard gelatin capsule. (Manufactured by: Trigonella MED Ltd., Mosonmagyaróvár, Hungary, OÉTI number: 6698/210, Expiry date: 31 August 2017).

Placebo product: Placebo, without active compound (filled with grits) in hard gelatin capsule (Manufactured by: Trigonella MED Ltd., Mosonmagyaróvár, Hungary).

For 10 days (from day 1 to 11) test or placebo product was self-administered by the subjects, 2 capsules p.o., three times a day. On the first day of the study, 2 capsules were administered, but only at noon and in the evening, while on the last day, 2 capsules were administered, only in the evening.

\subsection{Hyperinsulinemic Euglycemic Glucose Clamp (HEGC)}

The HEGC is considered the gold standard for the determination of insulin secretion and resistance. The method was described by DeFronzo et al. in 1979 [67] and was performed to estimate the whole body insulin sensitivity of the volunteers. The test was carried out on the first day prior to the treatment, and after 10 days of TFG or placebo treatment, on the eleventh day. Before HEGC, body weight and height recording and blood sampling for clinical chemistry-including insulin and $\mathrm{MCH}$ determination - was carried out. The principle of the method was to maintain euglycemia at clamped hyperinsulinemia. The average Glucose Infusion Rate (GIR), expressed in $\mathrm{mg} / \mathrm{kg} / \mathrm{min}$ necessary to compensate the hypoglycemic effect of the continuous insulin infusion is the accepted measuring unit for determining tissue insulin sensitivity.

All studies were performed at 7.00 a.m., after a $12 \mathrm{~h}$ overnight starvation. Two peripheral veins were cannulated for both forearms: one antecubital vein to administer the continuous glucose and insulin infusions, and one forearm vein on the contralateral arm for blood sample collection.

Insulin infusion was prepared as follows: in a $50 \mathrm{~mL}$ syringe, $48 \mathrm{~mL}$ of physiological saline, $8 \times$ BSA units of Humulin R, Eli Lilly insulin, and $2 \mathrm{~mL}$ of the volunteer's own blood (to prevent insulin adhesion) were homogenized and administered via a precision perfusion pump to the volunteers. The priming infusion rate was $60 \mathrm{~mL} / \mathrm{h}$ for $4 \mathrm{~min}$, then $30 \mathrm{~mL} / \mathrm{h}$ for further $4 \mathrm{~min}$, followed by a maintenance rate of infusion that was $15 \mathrm{~mL} / \mathrm{h}$ (corresponding to $40 \mathrm{mU} / \mathrm{m}^{2} / \mathrm{min}$ of insulin) administered for $112 \mathrm{~min}$. The rate of the $20 \%$ dextrose infusion was adjusted to maintain the target blood glucose levels at $5.5 \pm 0.5 \mathrm{mmol} / \mathrm{L}$ (euglycemic range).

Blood glucose levels were determined every 5 min using Accu-Check blood glucose meter (Accu-Check, Roche Diagnostics, Budaörs, Hungary), utilizing the glucose oxidase method, and the glucose infusion rate was adjusted according to the blood glucose level. 
In a "steady state" condition, that is set during HEGC, usually in the 90th minute, the blood glucose levels are stabilized, so the rate of glucose infusion no longer requires modification, or needs to be minimally adjusted. The steady state glucose infusion rate (in the last $30 \mathrm{~min}$ ) was used to characterize insulin sensitivity [67].

After cessing the insulin infusion, the volunteers were strictly monitored, blood glucose levels were checked, and glucose infusion was administered in case of necessity.

An intensive care expert team was ready to treat any unwanted effects with special regards to events at risk of hypoglycemia during and following the glucose clamping.

Following HEGC, post-study laboratory investigations were performed within $24 \mathrm{~h}$ after the last treatment phase, and there was a closing visit after 30 days.

\subsection{Analytical Methods}

The laboratory parameters, including the liver function tests, kidney function tests, electrolyte determinations, hematology, urinalysis, fasting glucose and insulin $(0 \mathrm{~min})$, repeated glucose and insulin ( $60 \mathrm{~min}, 90 \mathrm{~min}, 120 \mathrm{~min}$ ) determinations were performed by the Department of Laboratory Medicine, University of Debrecen.

The MCH concentration was determined from blood samples separately taken into $10 \mathrm{~mL}$ EDTA (ethylenediamine-tetraacetic acid)-containing tubes, at 0 and $120 \mathrm{~min}$ on the 1 st and the 11 th days using a novel MCH radioimmunoassay developed by the researchers of the Department of Pharmacology and Pharmacotherapy, University of Debrecen.

\subsection{Measurement of Melanin-Concentrating Hormone}

The EDTA-tubes were centrifuged ( $4000 \mathrm{rpm}, 4^{\circ} \mathrm{C}, 15 \mathrm{~min}$ ), and the supernatants were further processed for radioimmunoassay (RIA) analysis of $\mathrm{MCH}$-like immunoreactivity (MCH-LI). The collected plasma samples were stored at $-80^{\circ} \mathrm{C}$ until RIA determination.

Due to the low circulating levels of $\mathrm{MCH}$ in plasma, a minimum of $1 \mathrm{~mL}$ plasma was required for the accurate determination by radioimmunoassay. Collected plasma samples were thawed, and during extraction procedures, samples and extraction reagents were stored in an ice water bath. Extraction was performed in the polypropylene RIA tubes $(5 \mathrm{~mL}, 12 \times 75 \mathrm{~mm})$. For precipitation of plasma proteins, $1 \mathrm{~mL}$ plasma was added to $3 \mathrm{~mL} 96 \%$ ethyl alcohol. After mixing, the samples were incubated in an ice bath for $30 \mathrm{~min}$. After centrifugation $\left(4000 \mathrm{rpm}, 4{ }^{\circ} \mathrm{C}, 10 \mathrm{~min}\right.$ ) the supernatants were decanted into RIA tubes and evaporated to dryness using nitrogen stream without heat. The dried samples were stored at $-80^{\circ} \mathrm{C}$ prior to RIA determination. In the RIA process the samples were re-dissolved in $800 \mu \mathrm{L}$ assay buffer and assayed directly in these tubes. In our RIA examination MCH specific antiserum $(\mathrm{MCH} 1 / 5)$ was applied, which was raised against a conjugate of rat $\mathrm{MCH}$ and bovine serum albumin (BSA) coupled by glutaraldehyde in rabbits. Rat $\mathrm{MCH}$ peptide was used as a RIA standard. The range of concentration was between 0 and $200 \mathrm{fmol} / \mathrm{mL}$. Mono-125I-labeled MCH was applied as a RIA tracer prepared in our isotope laboratory. Our assay buffer $(0.05 \mathrm{~mol} / \mathrm{L}, \mathrm{pH} 7.4$ phosphate buffer $)$ contained $0.1 \mathrm{M} \mathrm{NaCl}, 0.05 \% \mathrm{NaN} 3,0.25 \%$ bovine serum albumin (BSA, Sigma-Aldrich, St. Louis, MO, USA). The $1 \mathrm{~mL}$ incubation mixture contained $100 \mu \mathrm{L} \mathrm{MCH}$ standards, $100 \mu \mathrm{L}$ antiserum (working dilution 1:3500), $100 \mu \mathrm{L}$ RIA tracer (3000 cpm/tube) and the assay puffer. After $48 \mathrm{~h}$ incubation at $4{ }^{\circ} \mathrm{C}$ the antibody-bound peptide was separated from the free peptide by addition of $100 \mu \mathrm{L}$ separating suspension (10 g charcoal, $1 \mathrm{~g}$ dextran and $0.5 \mathrm{~g}$ commercial fat-free milk powder in $100 \mathrm{~mL}$ distilled water). After centrifugation ( $4000 \mathrm{rpm}, 4{ }^{\circ} \mathrm{C}, 20 \mathrm{~min}$ ) the tubes were gently decanted. Radioactivity of the precipitates was measured in a NZ310 type gamma counter (Gamma, Budapest, Hungary). The MCH-LI of the unknown samples was read from the calibration curve.

Antiserum "MCH1/5", used in the assay turned out to be C-terminal specific without affinity for the structurally similar peptides. The average ID50 value of the calibration curves was $11.93 \pm 1.78 \mathrm{fmol} / \mathrm{mL}$, determined in ten consecutive assays. Detection limit of the assay for rat 
$\mathrm{MCH}$ was $0.2 \mathrm{fmol} / \mathrm{mL}$. Intra-assay and inter-assay coefficients of variation were $6.84 \%$ and $9.32 \%$, respectively [35].

\subsection{Assesment of Insulin-Sensitivity}

Based on the raw data obtained using the HEGC method we can calculate the GIR, the metabolic clearance rate of insulin (MCRI), the insulin sensitivity index (ISI) and the quantitative insulin sensitivity check index (QUICKI) that are indicators of the whole body insulin sensitivity [68-70].

Formulas for calculations:

GIR = glucose infusion rate $[(\mu \mathrm{L} / \mathrm{min}) / \mathrm{BW}($ body weight in $\mathrm{kg}) \times 100] \times(20 \times 10)$

MCRI = (insulin infusion rate/steady state plasma insulin concentration - basal plasma insulin concentration) $\times 1000$, expressed in $\mathrm{mU} / \mathrm{m}^{2} / \mathrm{min}$.

ISI $=($ glucose infusion rate/steady state plasma insulin concentration $) \times 100$, expressed in $\mathrm{mg} / \mathrm{kg} / \mathrm{min} / \mathrm{mU} / \mathrm{mL}$.

QUICKI $=1 / \log$ Insuline $(0 \mathrm{~min})(\mu \mathrm{IU} / \mathrm{mL})+\log$ Glucose $(0 \mathrm{~min})(\mathrm{mg} / \mathrm{dL})$.

To estimate insulin resistance and pancreatic $\beta$-cell functions we used the widely approved homeostatic model of assessment [69-73].

The HOMA-IR $($ HOMA for insulin resistance $)=($ FPI $\times$ FPG $) / 22.5$ and the HOMA-B $($ HOMA of $\beta$-cell function $)=(20 \times \mathrm{FPI}) /(\mathrm{FPG}-3.5)$ were calculated as proposed by $[72,74]$, where FPI $=$ fasting plasma insulin $(\mu \mathrm{IU} / \mathrm{mL})$ and $\mathrm{FPG}=$ fasting plasma glucose $(\mathrm{mmol} / \mathrm{L})$.

\subsection{Data Analysis and Statistics}

Statistical analysis was carried out using the SAS system, version 9.2 (SAS Institute, Cary, NC, USA). The safety laboratory parameters were statistically analyzed by repeated measures ANOVA. The efficacy parameter for insulin sensitivity (GIR) for the fenugreek and placebo treatment groups was statistically analyzed by the repeated measures ANOVA in conjunction with Tukey's HSD. (GIR was also separately analyzed with paired Student's $t$-test). The results were considered significantly different if $p \leq 0.05$. To analyze the association between $\mathrm{MCH}$ vs. glucose, insulin and serum lipid (total cholesterol, LDL-cholesterol, HDL-cholesterol and triglycerides) levels, "correlation" and "linear regression" statistical methods were used.

\section{Conclusions}

Oral preparation of fenugreek seeds improves glucose metabolism by its insulin-sensitizing effect and involves mechanisms that notably include fenugreek intake-related reduction of circulating $\mathrm{MCH}$ levels. Since the fenugreek-associated increase in insulin-sensitivity was the most powerful in patients with the lowest baseline GIR parameters, we conclude that it would be valued to repeat these experiments on a larger number of patients who manifest T2DM. Our results presented here suggest that members of MCH-related signal transduction pathways could become new molecular targets of drug discovery and development in the future.

Supplementary Materials: The following are available online at www.mdpi.com/1422-0067/19/3/771/s1.

Acknowledgments: The work/publication was supported by the GINOP-2.3.4-15-2016-00002 project. The project is co-financed by the European Union and the European Regional Development Fund. This work was also supported in part by AGR-PIAC-13-1-2013-0008. The authors are sincerely grateful to Stephanie C. Fox, of QueenBeeEdit in Bloomfield, CT, USA, for her hard work in organizing, formatting, and editing this article.

Author Contributions: Rita Kiss: HEGC, treatments, data analysis statistical analysis; Katalin Szabo: study design, RIA, Rudolf Gesztelyi: study design, statistical analysis, Sandor Somodi: HEGC, treatment, data analysis, Peter Kovacs: Clinical study leader, HEGC, Zoltan Szabo: treatment, HEGC, Jozsef Nemeth: RIA; Daniel Priksz: statistics; Andrea Kurucz: statistical analysis, manuscript preparation; Bela Juhasz: study design, treatments, HEGC, corresponding author; and Zoltan Szilvassy: study design, data analysis.

Conflicts of Interest: The authors declare no conflict of interest. 


\section{References}

1. Tseung, J. Robbins and Cotran Pathologic Basis of Disease: 7th Edition. Pathology 2005, 37, 190. [CrossRef]

2. Olokoba, A.B.; Obateru, O.A.; Olokoba, L.B. Type 2 Diabetes Mellitus: A Review of Current Trends. Oman Med. J. 2012, 27, 269-273. [CrossRef] [PubMed]

3. Lionetti, L.; Mollica, M.P.; Sica, R.; Donizzetti, I.; Gifuni, G.; Pignalosa, A.; Cavaliere, G.; Putti, R. Differential Effects of High-Fish Oil and High-Lard Diets on Cells and Cytokines Involved in the Inflammatory Process in Rat Insulin-Sensitive Tissues. Int. J. Mol. Sci. 2014, 15, 3040-3063. [CrossRef] [PubMed]

4. Lowell, B.B.; Shulman, G.I. Mitochondrial Dysfunction and Type 2 Diabetes. Science 2005, 307, $384-387$. [CrossRef] [PubMed]

5. Tubbs, E.; Chanon, S.; Robert, M.; Bendridi, N.; Bidaux, G.; Chauvin, M.-A.; Ji-Cao, J.; Durand, C.; Gauvrit-Ramette, D.; Vidal, H.; et al. Disruption of Mitochondria-Associated Endoplasmic Reticulum Membranes (MAMs) Integrity Contributes to Muscle Insulin Resistance in Mice and Humans. Diabetes 2018. [CrossRef] [PubMed]

6. Engin, A.B.; Tsatsakis, A.M.; Tsoukalas, D.; Engin, A. Do flavanols-rich natural products relieve obesity-related insulin resistance? Food Chem. Toxicol. 2018, 112, 157-167. [CrossRef] [PubMed]

7. Kloppel, G.; Lohr, M.; Habich, K.; Oberholzer, M.; Heitz, P.U. Islet pathology and the pathogenesis of type 1 and type 2 diabetes mellitus revisited. Surv. Syn. Pathol. Res. 1985, 4, 110-125.

8. Kassaian, N.; Azadbakht, L.; Forghani, B.; Amini, M. Effect of fenugreek seeds on blood glucose and lipid profiles in type 2 diabetic patients. Int. J. Vitam. Nutr. Res. 2009, 79, 34-39. [CrossRef] [PubMed]

9. Tabish, S.A. Is Diabetes Becoming the Biggest Epidemic of the Twenty-first Century? Int. J. Health Sci. 2007, $1,5-8$.

10. Wild, S.; Roglic, G.; Green, A.; Sicree, R.; King, H. Global prevalence of diabetes: estimates for the year 2000 and projections for 2030. Diabetes Care 2004, 27, 1047-1053. [CrossRef] [PubMed]

11. Guariguata, L.; Whiting, D.R.; Hambleton, I.; Beagley, J.; Linnenkamp, U.; Shaw, J.E. Global estimates of diabetes prevalence for 2013 and projections for 2035. Diabetes Res. Clin. Pract. 2014, 103, 137-149. [CrossRef] [PubMed]

12. Chiasson, J.-L.; Josse, R.G.; Gomis, R.; Hanefeld, M.; Karasik, A.; Laakso, M. Acarbose for prevention of type 2 diabetes mellitus: The STOP-NIDDM randomised trial. Lancet 2002, 359, 2072-2077. [CrossRef]

13. Eriksson, K.F.; Lindgarde, F. Prevention of type 2 (non-insulin-dependent) diabetes mellitus by diet and physical exercise. The 6-year Malmo feasibility study. Diabetologia 1991, 34, 891-898. [CrossRef] [PubMed]

14. Gerstein, H.C.; Yusuf, S.; Bosch, J.; Pogue, J.; Sheridan, P.; Dinccag, N.; Hanefeld, M.; Hoogwerf, B.; Laakso, M.; Mohan, V.; et al. Effect of rosiglitazone on the frequency of diabetes in patients with impaired glucose tolerance or impaired fasting glucose: A randomised controlled trial. Lancet 2006, 368, 1096-1105. [PubMed]

15. Knowler, W.C.; Barrett-Connor, E.; Fowler, S.E.; Hamman, R.F.; Lachin, J.M.; Walker, E.A.; Nathan, D.M. Reduction in the incidence of type 2 diabetes with lifestyle intervention or metformin. N. Engl. J. Med. 2002, 346, 393-403. [PubMed]

16. Basch, E.; Ulbricht, C.; Kuo, G.; Szapary, P.; Smith, M. Therapeutic applications of fenugreek. Altern. Med. Rev. 2003, 8, 20-27. [PubMed]

17. Al-Asadi, J. Therapeutic Uses of Fenugreek (Trigonella foenum-graecum L.). Am. J. Soc. Issues Hum. 2014. Special issue.

18. Verma, N.; Usman, K.; Patel, N.; Jain, A.; Dhakre, S.; Swaroop, A.; Bagchi, M.; Kumar, P.; Preuss, H.G.; Bagchi, D. A multicenter clinical study to determine the efficacy of a novel fenugreek seed (Trigonella foenum-graecum) extract (Fenfuro ${ }^{\mathrm{TM}}$ ) in patients with type 2 diabetes. Food Nutr. Res. 2016, 60. [CrossRef] [PubMed]

19. Losso, J.N.; Holliday, D.L.; Finley, J.W.; Martin, R.J.; Rood, J.C.; Yu, Y.; Greenway, F.L. Fenugreek bread: A treatment for diabetes mellitus. J. Med. Food 2009, 12, 1046-1049. [CrossRef] [PubMed]

20. Grover, J.K.; Yadav, S.; Vats, V. Medicinal plants of India with anti-diabetic potential. J. Ethnopharmacol. 2002, 81, 81-100. [CrossRef]

21. Mathern, J.R.; Raatz, S.K.; Thomas, W.; Slavin, J.L. Effect of Fenugreek Fiber on Satiety, Blood Glucose and Insulin Response and Energy Intake in Obese Subjects. Phytother. Res. 2009, 23, 1543-1548. [CrossRef] [PubMed] 
22. Wani, S.A.; Kumar, P. Fenugreek: A review on its nutraceutical properties and utilization in various food products. J. Saudi Soc. Agric. Sci. 2016. [CrossRef]

23. Sulieman, A.M.; Ahmed, H.E.; Abdelrahim, A.M. The Chemical Composition of Fenugreek (Trigonella foenum graceum L) and the Antimicrobial Properties of its Seed Oil. Gezira J. Eng. Appl. Sci. 2008, 3, 52-71.

24. Uemura, T.; Goto, T.; Kang, M.S.; Mizoguchi, N.; Hirai, S.; Lee, J.Y.; Nakano, Y.; Shono, J.; Hoshino, S.; Taketani, K.; et al. Diosgenin, the main aglycon of fenugreek, inhibits LXRalpha activity in HepG2 cells and decreases plasma and hepatic triglycerides in obese diabetic mice. J. Nutr. 2011, 141, 17-23. [CrossRef] [PubMed]

25. Chevassus, H.; Molinier, N.; Costa, F.; Galtier, F.; Renard, E.; Petit, P. A fenugreek seed extract selectively reduces spontaneous fat consumption in healthy volunteers. Eur. J. Clin. Pharmacol. 2009, 65, 1175-1178. [CrossRef] [PubMed]

26. Tharaheswari, M.; Jayachandra Reddy, N.; Kumar, R.; Varshney, K.C.; Kannan, M.; Sudha Rani, S. Trigonelline and diosgenin attenuate ER stress, oxidative stress-mediated damage in pancreas and enhance adipose tissue PPAR $\gamma$ activity in type 2 diabetic rats. Mol. Cell. Biochem. 2014, 396, 161-174. [CrossRef] [PubMed]

27. Neelakantan, N.; Narayanan, M.; de Souza, R.J.; van Dam, R.M. Effect of fenugreek (Trigonella foenum-graecum L.) intake on glycemia: A meta-analysis of clinical trials. Nutr. J. 2014, 13, 7. [CrossRef] [PubMed]

28. Kawauchi, H. Chemistry of proopiocortin-related peptides in the salmon pituitary. Arch. Biochem. Biophys. 1983, 227, 343-350. [CrossRef]

29. Presse, F.; Nahon, J.-L. Mch. In Handbook of Biologically Active Peptides; Academic Press: Cambridge, MA, USA, 2013; pp. 828-837.

30. David, D.J.; Klemenhagen, K.C.; Holick, K.A.; Saxe, M.D.; Mendez, I.; Santarelli, L.; Craig, D.A.; Zhong, H.; Swanson, C.J.; Hegde, L.G.; et al. Efficacy of the MCHR1 antagonist $\mathrm{N}$-[3-(1-\{[4-(3,4-difluorophenoxy)phenyl]methyl\}(4-piperidyl))-4-methylphenyl]-2-m ethylpropanamide (SNAP 94847) in mouse models of anxiety and depression following acute and chronic administration is independent of hippocampal neurogenesis. J. Pharmacol. Exp. Ther. 2007, 321, 237-248. [PubMed]

31. Gavrila, A.; Chan, J.L.; Miller, L.C.; Heist, K.; Yiannakouris, N.; Mantzoros, C.S. Circulating melanin-concentrating hormone, agouti-related protein, and alpha-melanocyte-stimulating hormone levels in relation to body composition: Alterations in response to food deprivation and recombinant human leptin administration. J. Clin. Endocrinol. Metab. 2005, 90, 1047-1054. [CrossRef] [PubMed]

32. Philippe, C.; Nics, L.; Zeilinger, M.; Kuntner, C.; Wanek, T.; Mairinger, S.; Shanab, K.; Spreitzer, H.; Viernstein, H.; Wadsak, W.; et al. Preclinical in vitro \& in vivo evaluation of [11C]SNAP-7941-The first PET tracer for the melanin-concentrating hormone receptor 1. Nucl. Med. Biol. 2013, 40, 919-925. [PubMed]

33. Imbernon, M.; Beiroa, D.; Vázquez, M.J.; Morgan, D.A.; Veyrat-Durebex, C.; Porteiro, B.; Díaz-Arteaga, A.; Senra, A.; Busquets, S.; Velásquez, D.A.; et al. Central Melanin-Concentrating Hormone Influences Liver and Adipose Metabolism Via Specific Hypothalamic Nuclei and Efferent Autonomic/JNK1 Pathways. Gastroenterology 2013, 144, 636-649. [CrossRef] [PubMed]

34. Baker, B.I. Melanin-concentration hormone updated functional considerations. Trends Endocrinol. Metab. 1994, 5, 120-126. [CrossRef]

35. Lelesz, B.; Szilvássy, Z.; Tóth, G.K.; Tóth, A.; Enyedi, A.; Felszeghy, E.; Varga, A.; Juhász, B.; Németh, J. Radioanalytical methods for the measurement of melanin-concentrating hormone $(\mathrm{MCH})$ and detection its receptor in rat tissues. J. Radioanal. Nucl. Chem. 2016, 310, 1325-1333. [CrossRef]

36. Naufahu, J.; Alzaid, F.; Fiuza Brito, M.; Doslikova, B.; Valencia, T.; Cunliffe, A.; Murray, J.F. Melanin-concentrating hormone in peripheral circulation in the human. J. Endocrinol. 2017, 232, 513-523. [CrossRef] [PubMed]

37. Nahon, J.-L. The melanocortins and melanin-concentrating hormone in the central regulation of feeding behavior and energy homeostasis. C. R. Biol. 2006, 329, 623-638. [CrossRef] [PubMed]

38. Jeon, M.K.; Cheon, H.G. Promising strategies for obesity pharmacotherapy: Melanocortin-4 (MC-4) receptor agonists and melanin-concentrating hormone $(\mathrm{MCH})$ receptor-1 antagonists. Curr. Top. Med. Chem. 2009, 9, 504-538. [CrossRef] [PubMed]

39. MacNeil, D.J. The Role of Melanin-Concentrating Hormone and Its Receptors in Energy Homeostasis. Front. Endocrinol. 2013, 4, 49. [CrossRef] [PubMed] 
40. Wu, M.; Li, Y.; Fu, X.; Wang, J.; Zhang, S.; Yang, L. Profiling the Interaction Mechanism of Quinoline/Quinazoline Derivatives as MCHR1 Antagonists: An in Silico Method. Int. J. Mol. Sci. 2014, 15, 15475-15502. [CrossRef] [PubMed]

41. Wang, S.; Behan, J.; O'Neill, K.; Weig, B.; Fried, S.; Laz, T.; Bayne, M.; Gustafson, E.; Hawes, B.E. Identification and Pharmacological Characterization of a Novel Human Melanin-concentrating Hormone Receptor, MCH-R2. J. Biol. Chem. 2001, 276, 34664-34670. [CrossRef] [PubMed]

42. Kawata, Y.; Okuda, S.; Hotta, N.; Igawa, H.; Takahashi, M.; Ikoma, M.; Kasai, S.; Ando, A.; Satomi, Y.; Nishida, M.; et al. A novel and selective melanin-concentrating hormone receptor 1 antagonist ameliorates obesity and hepatic steatosis in diet-induced obese rodent models. Eur. J. Pharmacol. 2017, 796, 45-53. [CrossRef] [PubMed]

43. Tadayyon, M.; Welters, H.J.; Haynes, A.C.; Cluderay, J.E.; Hervieu, G. Expression of melanin-concentrating hormone receptors in insulin-producing cells: $\mathrm{MCH}$ stimulates insulin release in RINm5F and CRI-G1 cell-lines. Biochem. Biophys. Res. Commun. 2000, 275, 709-712. [CrossRef] [PubMed]

44. Buijs, R.M.; Chun, S.J.; Niijima, A.; Romijn, H.J.; Nagai, K. Parasympathetic and sympathetic control of the pancreas: A role for the suprachiasmatic nucleus and other hypothalamic centers that are involved in the regulation of food intake. J. Comp. Neurol. 2001, 431, 405-423. [CrossRef]

45. Pereira-da-Silva, M.; De Souza, C.T.; Gasparetti, A.L.; Saad, M.J.; Velloso, L.A. Melanin-concentrating hormone induces insulin resistance through a mechanism independent of body weight gain. J. Endocrinol. 2005, 186, 193-201. [CrossRef] [PubMed]

46. Sasmal, P.K.; Sasmal, S.; Abbineni, C.; Venkatesham, B.; Rao, P.T.; Roshaiah, M.; Khanna, I.; Sebastian, V.J.; Suresh, J.; Singh, M.P.; et al. Synthesis and SAR studies of benzimidazole derivatives as melanin-concentrating hormone receptor 1 (MCHR1) antagonists: Focus to detune hERG inhibition. MedChemComm 2011, 2, 385-389. [CrossRef]

47. Bradley, R.L.; Kokkotou, E.G.; Maratos-Flier, E.; Cheatham, B. Melanin-concentrating hormone regulates leptin synthesis and secretion in rat adipocytes. Diabetes 2000, 49, 1073-1077. [CrossRef] [PubMed]

48. Haines, D.D.; Bak, I.; Ferdinandy, P.; Mahmoud, F.F.; Al-Harbi, S.A.; Blasig, I.E.; Tosaki, A. Cardioprotective effects of the calcineurin inhibitor FK506 and the PAF receptor antagonist and free radical scavenger, EGb 761, in isolated ischemic/reperfused rat hearts. J. Cardiovasc. Pharmacol. 2000, 35, 37-44. [CrossRef] [PubMed]

49. Gomori, A.; Ishihara, A.; Ito, M.; Mashiko, S.; Matsushita, H.; Yumoto, M.; Ito, M.; Tanaka, T.; Tokita, S.; Moriya, M.; et al. Chronic intracerebroventricular infusion of $\mathrm{MCH}$ causes obesity in mice. Melanin-concentrating hormone. Am. J. Pathophysiol. Endocrinol. Metab. 2003, 284, E583-E588. [CrossRef] [PubMed]

50. Qu, D.; Ludwig, D.S.; Gammeltoft, S.; Piper, M.; Pelleymounter, M.A.; Cullen, M.J.; Mathes, W.F.; Przypek, J.; Kanarek, R.; Maratos-Flier, E. A role for melanin-concentrating hormone in the central regulation of feeding behaviour. Nature 1996, 380, 243-247. [CrossRef] [PubMed]

51. Della-Zuana, O.; Presse, F.; Ortola, C.; Duhault, J.; Nahon, J.L.; Levens, N. Acute and chronic administration of melanin-concentrating hormone enhances food intake and body weight in Wistar and Sprague-Dawley rats. Int. J. Obes. 2002, 26, 1289-1295. [CrossRef] [PubMed]

52. Ludwig, D.S.; Tritos, N.A.; Mastaitis, J.W.; Kulkarni, R.; Kokkotou, E.; Elmquist, J.; Lowell, B.; Flier, J.S.; Maratos-Flier, E. Melanin-concentrating hormone overexpression in transgenic mice leads to obesity and insulin resistance. J. Clin. Investig. 2001, 107, 379-386. [CrossRef] [PubMed]

53. Marsh, D.J.; Weingarth, D.T.; Novi, D.E.; Chen, H.Y.; Trumbauer, M.E.; Chen, A.S.; Guan, X.-M.; Jiang, M.M.; Feng, Y.; Camacho, R.E.; et al. Melanin-concentrating hormone 1 receptor-deficient mice are lean, hyperactive, and hyperphagic and have altered metabolism. Proc. Nat. Acad. Sci. USA 2002, 99, 3240-3245. [CrossRef]

54. Chen, Y.; Hu, C.; Hsu, C.-K.; Zhang, Q.; Bi, C.; Asnicar, M.; Hsiung, H.M.; Fox, N.; Slieker, L.J.; Yang, D.D.; et al. Targeted Disruption of the Melanin-Concentrating Hormone Receptor-1 Results in Hyperphagia and Resistance to Diet-Induced Obesity. Endocrinology 2002, 143, 2469-2477. [CrossRef] [PubMed]

55. Jeon, J.Y.; Bradley, R.L.; Kokkotou, E.G.; Marino, F.E.; Wang, X.; Pissios, P.; Maratos-Flier, E. MCH-/- mice are resistant to aging-associated increases in body weight and insulin resistance. Diabetes 2006, 55, 428-434. [CrossRef] [PubMed]

56. Hervieu, G.; Volant, K.; Grishina, O.; Descroix-Vagne, M.; Nahon, J.-L. Similarities in Cellular Expression and Functions of Melanin-Concentrating Hormone and Atrial Natriuretic Factor in the Rat Digestive Tract. Endocrinology 1996, 137, 561-571. [CrossRef] [PubMed] 
57. Pissios, P.; Ozcan, U.; Kokkotou, E.; Okada, T.; Liew, C.W.; Liu, S.; Peters, J.N.; Dahlgren, G.; Karamchandani, J.; Kudva, Y.C.; et al. Melanin-concentrating hormone Is a Novel Regulator of Islet Function and Growth. Diabetes 2007, 56, 311-319. [CrossRef] [PubMed]

58. W Schwartz, M.; Gelling, R. Rats lighten up with MCH antagonist. Nat. Med. 2002, 8, 779-781. [CrossRef] [PubMed]

59. Konadhode, R.R.; Pelluru, D.; Shiromani, P.J. Neurons containing orexin or melanin-concentrating hormone reciprocally regulate wake and sleep. Front. Syst. Neurosci. 2015, 8, 244. [CrossRef] [PubMed]

60. Hausen, A.C.; Ruud, J.; Jiang, H.; Hess, S.; Varbanov, H.; Kloppenburg, P.; Brüning, J.C. Insulin-Dependent Activation of MCH Neurons Impairs Locomotor Activity and Insulin Sensitivity in Obesity. Cell Rep. 2016, 17, 2512-2521. [CrossRef] [PubMed]

61. Yang, J.; Yuan, C.; Wei, L.; Yi, F.; Song, F. Melanin-concentrating hormone receptor 2 affects 3T3-L1 preadipocyte differentiation. Mol. Cell. Endocrinol. 2009, 311, 11-17. [CrossRef] [PubMed]

62. Gaddam, A.; Galla, C.; Thummisetti, S.; Marikanty, R.K.; Palanisamy, U.D.; Rao, P.V. Role of Fenugreek in the prevention of type 2 diabetes mellitus in prediabetes. J. Diabetes Metab. Disord. 2015, 14, 74. [CrossRef] [PubMed]

63. Rafraf, M.; Malekiyan, M.; Asghari Jafarabadi, M.; Asgarzadeh, A.A.; Pourmoradian, S. Effect of Fenugreek Deeds on Serum Metabolic Factors and ICAM-1 (Intercellular adhesion molecule-1) levels in type 2 Diabetic Patients. ZUMS 2015, 23, 11-21.

64. Sauvaire, Y.; Petit, P.; Broca, C.; Manteghetti, M.; Baissac, Y.; Fernandez-Alvarez, J.; Gross, R.; Roye, M.; Leconte, A.; Gomis, R.; et al. 4-Hydroxyisoleucine: A Novel Amino Acid Potentiator of Insulin Secretion. Diabetes 1998, 47, 206-210. [CrossRef] [PubMed]

65. Nagulapalli Venkata, K.C.; Swaroop, A.; Bagchi, D.; Bishayee, A. A small plant with big benefits: Fenugreek (Trigonella foenum-graecum Linn.) for disease prevention and health promotion. Mol. Nutr. Food Res. 2017, 61. [CrossRef] [PubMed]

66. Fuller, S.; Stephens, J.M. Diosgenin, 4-Hydroxyisoleucine, and Fiber from Fenugreek: Mechanisms of Actions and Potential Effects on Metabolic Syndrome. Adv. Nutr. 2015, 6, 189-197. [CrossRef] [PubMed]

67. DeFronzo, R.A.; Tobin, J.D.; Andres, R. Glucose clamp technique: A method for quantifying insulin secretion and resistance. Am. J. Physiol. 1979, 237, E214-E223. [CrossRef] [PubMed]

68. Radikova, Z. Assessment of insulin sensitivity/resistance in epidemiological studies. Endocr. Regul. 2003, 37, 189-194. [PubMed]

69. Muniyappa, R.; Madan, R.; Quon, M.J. Assessing Insulin Sensitivity and Resistance in Humans. In Endotext; De Groot, L.J., Chrousos, G., Dungan, K., Feingold, K.R., Grossman, A., Hershman, J.M., Koch, C., Korbonits, M., McLachlan, R., New, M., et al., Eds.; Endotext: South Dartmouth, MA, USA, 2000.

70. Gutch, M.; Kumar, S.; Razi, S.; Gupta, K.; Gupta, A. Assessment of insulin sensitivity/resistance. Indian J. Endocrinol. Metab. 2015, 19, 160-164. [CrossRef] [PubMed]

71. Bradley, R.; Oberg, E.B.; Calabrese, C.; Standish, L.J. Algorithm for complementary and alternative medicine practice and research in type 2 diabetes. J. Altern. Complement. Med. 2007, 13, 159-175. [CrossRef] [PubMed]

72. Wallace, T.M.; Levy, J.C.; Matthews, D.R. Use and abuse of HOMA modeling. Diabetes Care 2004, 27, 1487-1495. [CrossRef] [PubMed]

73. Song, Y.; Manson, J.E.; Tinker, L.; Howard, B.V.; Kuller, L.H.; Nathan, L.; Rifai, N.; Liu, S. Insulin sensitivity and insulin secretion determined by homeostasis model assessment and risk of diabetes in a multiethnic cohort of women: The Women's Health Initiative Observational Study. Diabetes Care 2007, 30, 1747-1752. [CrossRef] [PubMed]

74. Matthews, D.R.; Hosker, J.P.; Rudenski, A.S.; Naylor, B.A.; Treacher, D.F.; Turner, R.C. Homeostasis model assessment: Insulin resistance and beta-cell function from fasting plasma glucose and insulin concentrations in man. Diabetologia 1985, 28, 412-419. [CrossRef] [PubMed]

(C) 2018 by the authors. Licensee MDPI, Basel, Switzerland. This article is an open access article distributed under the terms and conditions of the Creative Commons Attribution (CC BY) license (http:/ / creativecommons.org/licenses/by/4.0/). 